\title{
An X-Ray Scattering Study of MGA-95 and ESPA Composite Membranes
}

\author{
V.Yu. Popov, I.V. Khorokhorina, Yu.M. Golovin, V.M. Polikarpov and S.I. Lazarev* \\ Department of Applied Geometry and Computer Graphics, Tambov State Technical University, \\ 112, Michurinskaya St., Tambov, 392032, Russian Federation \\ * Corresponding author. Tel.: + 7 (4752) 6303 70.E-mail: geometry@mail.nnn.tstu.ru
}

\begin{abstract}
In this paper, we describe the results of the study of an MGA-95 semipermeable composite membrane with amorphous and crystalline regions, considering the effect of the three processes - migration, diffusion and fluid convection of solute and solvent. It was found that during swelling the supramolecular structure of the membrane material undergoes changes caused by deformation of the crystalline and amorphous regions of the membrane sample. The data on the amorphous regions for air-dry, water-saturated and working semipermeable membrane samples were analyzed. The comparative analysis of the diffraction patterns of an MGA-95 membrane showed that the external impact does not change the intramolecular structure of the membrane. Using the experimental data and the method of small-angle X-ray scattering we calculated the size of pores for MGA-95 and ESPA composite membranes. The findings led to the conclusion about the relative uniformity of the pore distribution in the thickness of the active layer of the membrane, and made it possible to determine their configuration. The data on the pore structure morphology of semipermeable membranes indicated that sorption region of MGA-95 and ESPA membranes was formed by pores of different types with varied surface morphology; smaller radius pores had a smoother surface, while larger pores had a rough surface. The number of larger radius pores -12.9 and $16.8 \mathrm{~nm}$ were equal to 20 and $35.6 \%$ for MGA-95 and ESPA, respectively. Specific surface values for MGA-95 was $S_{\mathrm{sp}}=9.15 \cdot 10^{7} \mathrm{~m}^{-1}$ and for ESPA it was $S_{\mathrm{sp}}=5.95 \cdot 10^{7} \mathrm{~m}^{-1}$.
\end{abstract}

\section{Keywords}

Membrane; amorphous structure; capillaries; crystallinity; membrane; morphology; pore radius; specific surface.

(c) V.Yu. Popov, I.V. Khorokhorina, Yu.M. Golovin, V.M. Polikarpov and S.I. Lazarev, 2016

\section{Introduction}

The movement of solution ions, solvent molecules and solute inside the capillary (pores) of the membrane is determined by the superposition of the three processes - migration, diffusion and convection. Generation of kinetic effects during swelling occurs with the formation of electrical double layer (EDL) at the ion-forming solid phase; EDL consists of the inner layer of adsorbed ions - the Stern layer, and the layer of diffuse moving counterions. In this case, the total potential drop (EDL) from the charge-forming surface is composed of the inner layer potential, the diffuse part potential and the $\zeta$-potential of the solvent $[1-5]$.

Following the logic of the EDL formation, one can confidently say that in the adsorption process water molecules fill the capillary-porous structure of the membrane, embedding into the surface of the ions forming potential due to donor-acceptor bond. Thus, the degree of filling of the pores (capillary) increases, causing the expansion of the Stern layer with structured water molecules, removing the diffusion layer and leading to a decrease in $\zeta$-potential.

Obviously, the formation of strong hydrogen bonds with the surface ions of pores quite easily leads to violations of the supramolecular structure of the composite membrane. The penetration of the solvent or solute, given the specifics of the structure of cellulose acetate membranes, is possible by the mechanisms of molecular diffusion through monolithic layers and capillary absorption of channels or voids of the membrane material.

This is probably due to the fact that fluid flow in the pores is conditioned by the structural changes of the polymer semipermeable membrane, i.e. the presence of amorphous regions. 


\section{Experimental}

The X-ray diffraction measurements were conducted at large angles $2 \theta$ from $2-40^{\circ}$ in the reflection geometry using $\mathrm{Cu}_{\alpha} \quad(\lambda=1.54 \AA)$ radiation monochromatized with a Ni-filter on the DRON-3 diffractometer with automatic recording on the PC. We studied the X-ray spectra of the new, water-saturated and working MGA-95 and ESPA composite membrane samples. The obtained diffraction patterns are shown in Fig. 1, 2.

\section{Results and Discussion}

The recorded X-ray diffraction patterns demonstrated diffuse low-intensity peaks with maxima at $2 \theta$ angles of $8.4,16.5,22.5$ and $25.5^{\circ}$. It is evident that intensity undergoes redistribution and the diffuse component of scattering increases in the watersaturated sample.

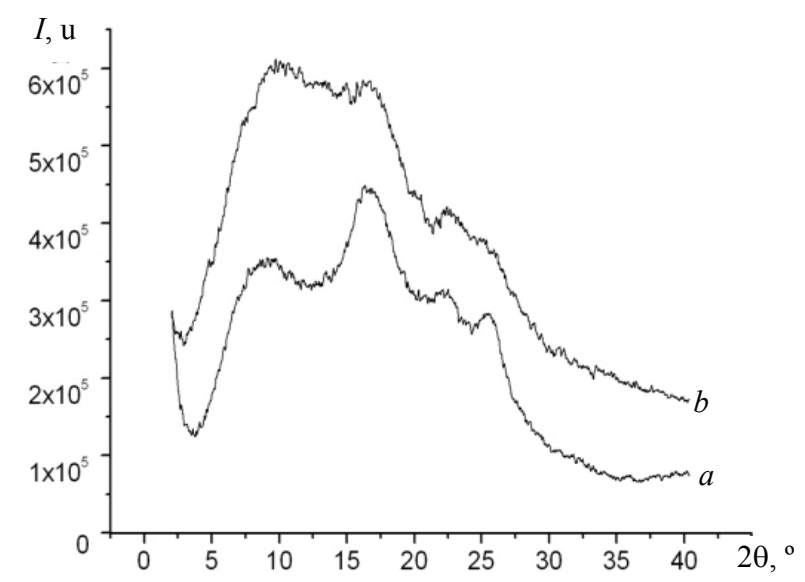

Fig. 1. X-ray diffraction patterns recorded in the reflection geometry for: $a$-dry; $b$ - working MGA-95 membrane samples

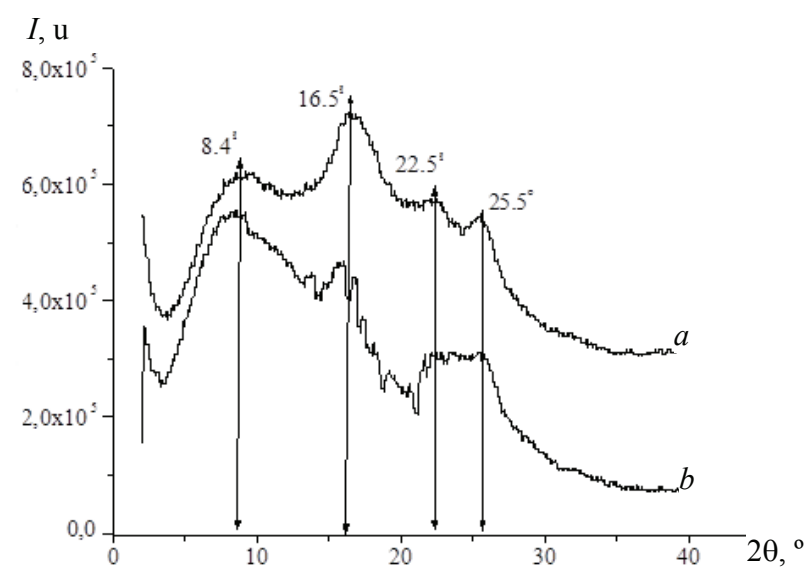

Fig. 2. X-ray diffraction patterns recorded in the reflection geometry for the $(a)$ - new sample; $(b)$ - working sample of the MGA-95 polymer membrane
However, the position of the X-ray scattering peaks at angles of $16.5,22.5$ and $25.5^{\circ}$ for the membrane samples in different states does not change. At the same time, the peak at an angle of $8.4^{\circ}$ undergoes not only a significant expansion, but also a shift to larger angles of $9.6^{\circ}$ for the water-saturated membrane sample.

The comparison of our results with experimental data [6] suggests that the X-ray scattering curves are typical of cellulose acetates formed from solutions. In [6] we noted that formation of mesophase with increasing polymer concentration causes an increase in the intensity of the X-ray reflection at $2 \theta$ angles of 7- $8^{\circ}$ and a decrease in the reflections at $2 \theta$ angles of $20-21^{\circ}$, which are responsible for polymer crystallization The crystallographic calculations for reflections at angles of $2 \theta=16.5 ; 22.5 ; 25.5^{\circ}$ conducted by the Bragg equation

$$
d=\lambda(2 \sin \theta)^{-1}
$$

gave the following interplanar distances $d_{16.5}=$ $=0.597 \mathrm{~nm} ; d_{22.5}=0.439 \mathrm{~nm} ; d_{25.5}=0.387 \mathrm{~nm}$, which is consistent with the crystal lattice parameters of $\alpha_{1}$ cellulose phase in the radial diffraction of the atoms located in (100), (010) and (110) crystallographic planes: Thus, the reflections at diffraction $2 \theta$ angles of $16.5-22.5^{\circ}$ should be identified as the structural state of the crystalline portion of the cellulose acetate.

In [6] we noted that the reflection at the angle of $2 \theta=8.4^{\circ}$ is attributed to X-ray diffraction of the atoms in the non-monocrystalline amorphous region of the heterogeneous membrane structure. The comparison of diffraction patterns (Fig. 2) of the new and working membrane samples showed that the position of reflections for both samples does not undergo any changes, however, can observe decreased intensity at the angles of $16.5,22.5$ and $25.5^{\circ}$ in the working membrane sample (Fig. 2, curve $b$ ).

A coincidence of diffraction angles apparently indicates low sensitivity of macromolecules to mechanical and thermodynamic load under cyclic conditions. Diffuse reflections are due to various factors, in particular, to the presence of solvent or solution remainders in the pores or on the surface of the membrane and residual diffractive changes in the general structure of the membrane.

In order to explain these experimental data about amorphous crystalline polymer membranes, it was necessary to find the ratio of crystalline and amorphous phases in them.

X-ray determination of the degree of crystallinity (CD) was conducted by the Agarwal-Till method [7], which is based on separation of reflections in 
crystalline and amorphous phases in the diffraction patterns of polymer, and the calculation is made by the equation:

$$
C D=\frac{I_{k}}{I_{k}+I_{a}} 100 \%
$$

where $I_{k}$ is total intensity of the crystalline phase, $I_{a}$ is total intensity of the amorphous phase.

The degree of crystallinity for the dry, waterswollen and working membrane samples was 57, 27 and $38 \%$, respectively. The calculated values of the degree of crystallinity indicate that the amorphous fraction in the swollen membrane sample has almost doubled. Such a change in the degree of crystallinity can be explained by the adsorption properties of water molecules, which have a low molecular volume and a strong tendency to donor-acceptor interactions with ions potential-forming surfaces of capillary-porous membrane space, breaking the intermolecular interactions of cellulose, thus increasing the proportion of amorphous regions. This explanation is consistent with the conclusions made by the authors in [8].

To understand and explain these experimental data, we need data on the amorphous phase in the membrane, and its modification in operation.

For this purpose we carried out measurements and theoretical analysis of the diffraction peaks at the angles of $2 \theta=8.4^{\circ}$ and $16.5^{\circ}$ (Fig. 3), using the Origin 6.0 program. It was found that the Gaussian bimodal with the characteristics of half width reflections from the amorphous phase gives the best approximation of these peaks.

The size of the amorphous region was determined by the Scherrer formula [9]

$$
L_{a}=\lambda\left(\beta \cos \frac{2 \theta}{2}\right)^{-1} \text {. }
$$

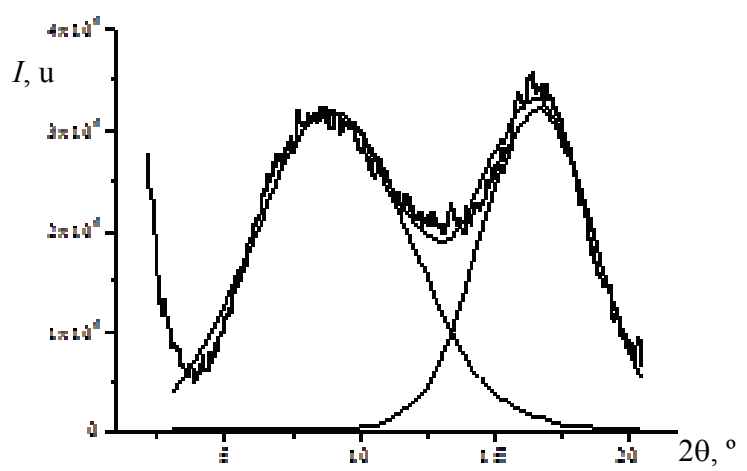

a)
Table 1

Parameters of the supramolecular structure of the MGA-95 membrane sample in the analysis

\begin{tabular}{|c|c|c|c|c|}
\hline \multirow[b]{2}{*}{$\begin{array}{l}\text { MGA-95 } \\
\text { sample }\end{array}$} & \multicolumn{4}{|c|}{ Amorphous diffraction peaks } \\
\hline & $\begin{array}{l}2 \theta \text { peak } \\
\text { position }\end{array}$ & $\begin{array}{l}\beta \text { peak half- } \\
\text { width (deg) }\end{array}$ & $\begin{array}{c}\beta_{i} \text { integral } \\
\text { half width } \\
\quad(\mathrm{deg})\end{array}$ & $L_{a}(\mathrm{~nm})$ \\
\hline Dry & $8.4^{\circ}$ & 5.4 & 6.9 & 1.7 \\
\hline $\begin{array}{l}\text { Water- } \\
\text { saturated } \\
\text { (swollen) }\end{array}$ & $9.6^{\circ}$ & 6.5 & 8.2 & 1.4 \\
\hline Working & $8.4^{\circ}$ & 5.6 & 7 & 1.6 \\
\hline
\end{tabular}
of amorphous diffraction patterns

The calculated parameters of the supramolecular structure of the membrane samples are listed in Table 1 below. As can be seen from the table, the diffraction peaks broaden and the amorphous phase decreases in size, and that is primarily due to the changes in the supramolecular structure of the membrane.

Based on these calculations, we can confidently state that during swelling, the supramolecular structure of the membrane material undergoes changes owing to deformation of both crystalline and amorphous components of sample phases.

It is known that the total porosity of cellulose acetate membranes reaches $75-80 \%[10,11]$. It can be determined experimentally by barometric studies; however, the structure of the pores and their size is quite difficult to estimate. Direct methods of determining the parameters are long electron microscopy and small-angle X-ray scattering (SAXS) $[12,13]$. We obtained experimental data on the size of gyration radius and radius of the membrane pores by small-angle X-ray scattering in an experimental setup.

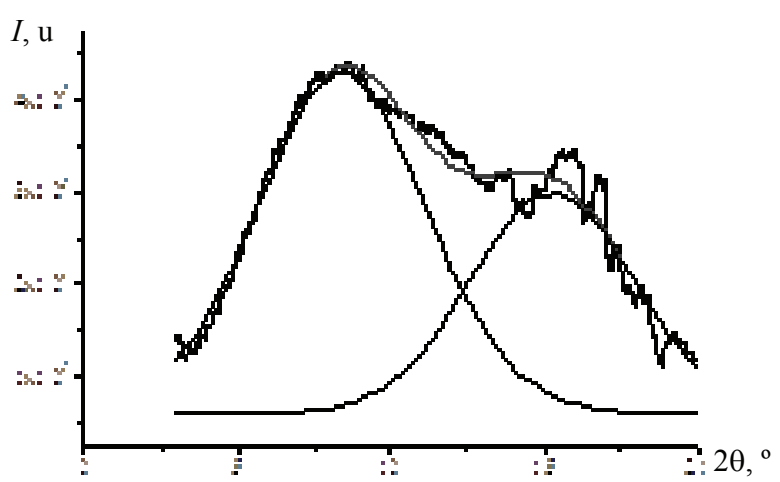

b)

Fig. 3. The diffraction peaks at scattering angles of $2 \theta=8.4^{\circ}$ and $16.5^{\circ}$ for $(a)$ the water-saturated membrane sample, $(b)$ the working membrane sample 


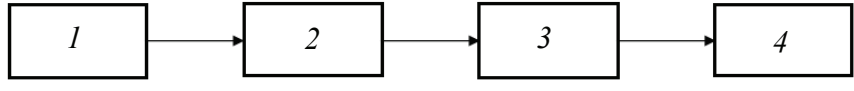

Fig 4. The experimental setup for the study of membrane pore regions by small-angle $X$-ray scattering:

1 - DRON-3 diffractometer; 2 - small-angle goniometer; 3 - BDS-6 meter; 4 - PC

The experimental setup for the study of pore radius by small-angle X-ray scattering method is shown in Fig. 4.

The scanning pitch was $1 \mathrm{~min}$ in an automatic mode. The plant operates as follows. A sample of the membrane is placed in a small-angle goniometer 2 , which operates from DRON-3 diffractometer. The data are received at BDS- 6 meter and interpreted by the computer 4. Experimental and computational interpretation of SAXS curves was carried out using the Origin 6.0 program [14].

The numerical value of the scattering vector modulus was calculated as a coordinate by the formula:

$$
s=(4 \pi / \lambda) \sin \theta,
$$

where $\theta$ is scattering angle, $\lambda=0.1542 \mathrm{~nm}$ is the wavelength of the copper X-rays. The dependence of the scattering intensity was constructed in the range of $s=0.14-3.0 \mathrm{~nm}^{-1}$.

Diffraction patterns in Fig. 5 and 6 show the correlation between the light refraction angle on the membrane and the number of pulses per unit time.

If we assume that the model exponents are ideal scattering curves of monodisperse systems with spherically uniform pores, the constructed curves can be considered as a superposition of at least three ideal exponents. This suggests that the membrane consists of pores of different sizes, ranging from small ones, contributing to scattering at large values of the scattering vector $(s)$, to the big ones, contributing to

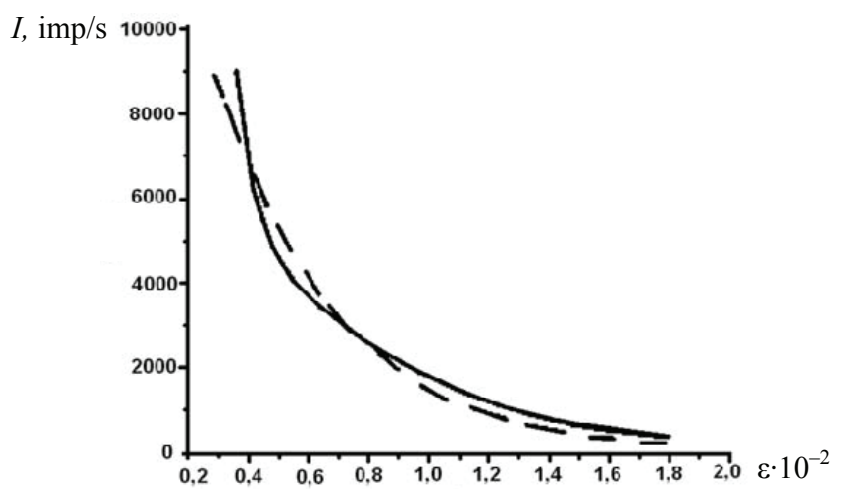

Fig. 5. Initial diffraction pattern for the ESPA membrane a solid line, for model curve - a dotted line scattering at small values of the scattering vector $(s)$ [2]. One should also pay attention to the smoothness of scattering curves for both membranes, which indicates an irregular distribution of pores in the membrane volume. Since the pore shape is not known beforehand, for the analysis of SAXS curves and calculation of the effective radius we used a tangent method [13, 15], according to which the scattering intensity in low angles can be calculated as a function

$$
I(s)=I(0) \exp \left(-R_{g}{ }^{2} s^{2} / 3\right),
$$

where the pore size is characterized by a universal parameter, a radius of gyration $R_{g}$. Refitting the curves $I(s)$ as functions

$$
\ln I(s)=f\left(s^{2}\right),
$$

we obtained the dependence

$$
\ln I(s)=\ln I(0)-R_{g}^{2} s^{2} / 3,
$$

where $\ln I(0)$ is scattering intensity in a zero diffraction angle.

Figures 7 and 8 show that curves $\ln I(s)$ have rectilinear portions with different angles of inclination. We calculated their slope ratio and the radius of gyration using the formula [16]:

$$
R_{g k}=0.644 \sqrt{\operatorname{tg} \alpha},
$$

where $k$ is the number of the corresponding component. In turn, the $\ln I_{k}(0)$ intercept of two straight lines on Y-axis, taking into account the background scattering, determines the contribution of a given type to the scattering intensity, thus making it possible to determine their number. The contribution of $k$-type of pores was calculated by the formula:

$$
\Delta \ln I_{k}=\ln I(0)-\ln I_{k}(0) .
$$

The consistent application of the tangent method to the obtained scattering curves made it possible to identify three regions, and their corresponding values of radius of gyration $R_{g k}$ of pores, and their relative volumes.

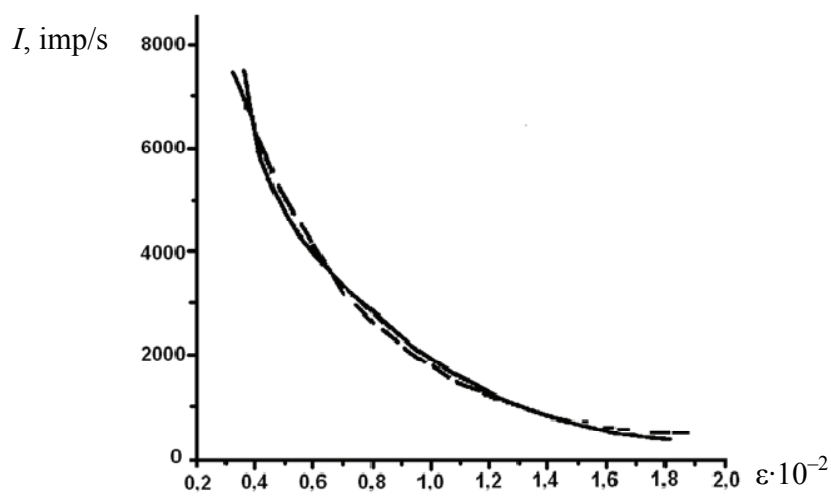

Fig. 6. Initial diffraction pattern for the MGA-95 membrane a solid line, for the model curve - a dotted line 


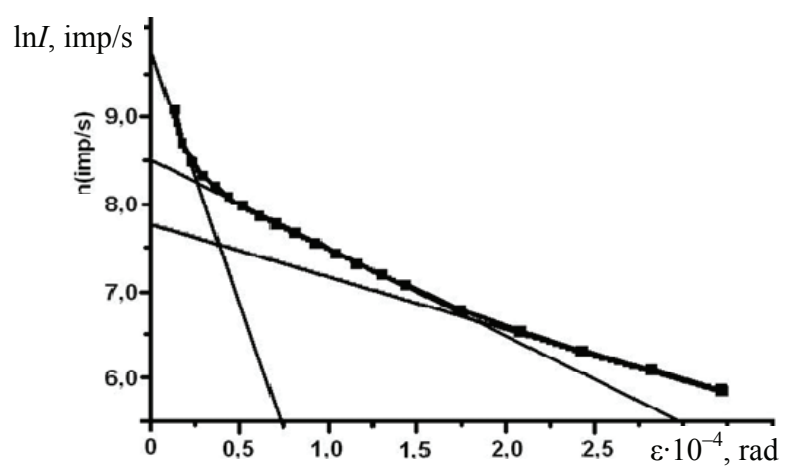

Fig. 7. Semilogarithmic representation for the ESPA membrane

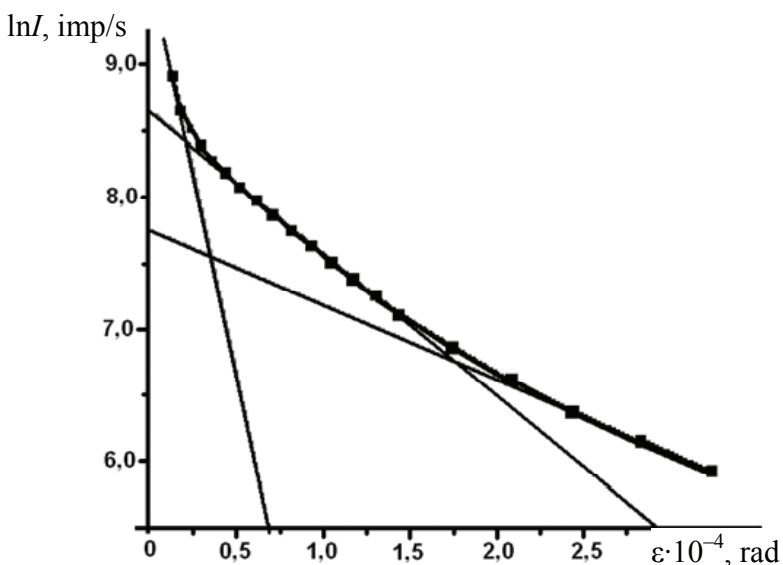

Fig. 8. Semilogarithmic representation for the MGA-95K membrane

The radius of gyration $R_{g k}$ allowed for calculation of the pore radius $r_{k}$ by the formula:

$$
r_{k}=\sqrt{5(0.644 \sqrt{\operatorname{tg} \alpha}) / 3} .
$$

The relative proportion of the pore size can be estimated by the method described in $[2,13]$, which indicates that the scattering energy for a zero angle of diffraction is proportional to the volume fraction $m_{k}$ of scattering particles (pores) where $m_{k}=\Delta I_{k}(0) / R_{g k}^{3}$. We analyzed the experimental data and determined the distribution of the relative amount of pores $m_{k}\left(r_{k}\right)$. It was found that the membranes mainly consisted of small size pores $\left(r_{\min } \sim 6,0-6,5 \mathrm{~nm}\right)$. The average effective radius of gyration, and accordingly the pore radius can be found as $[13,15]$

$$
R_{\text {gean }}=\frac{\sum m_{k} R_{g k}}{\sum m_{k}},
$$

For the ESPA membrane the radius of gyration was $R_{g \text { mean }}=8.9 \mathrm{~nm}$, and for the MGA-95K it was $R_{g \text { mean }}=9.0 \mathrm{~nm}$. The pore radii, in turn, were calculated from the model curves and equaled to $R_{g \text { mean }}=5.7 \mathrm{~nm}\left(r_{\text {mean }}=7.3 \mathrm{~nm}\right)$ and $R_{g \text { mean }}=5.0 \mathrm{~nm}$ $\left(r_{\text {mean }}=6.5 \mathrm{~nm}\right)$ for the ESPA and MGA-95K,

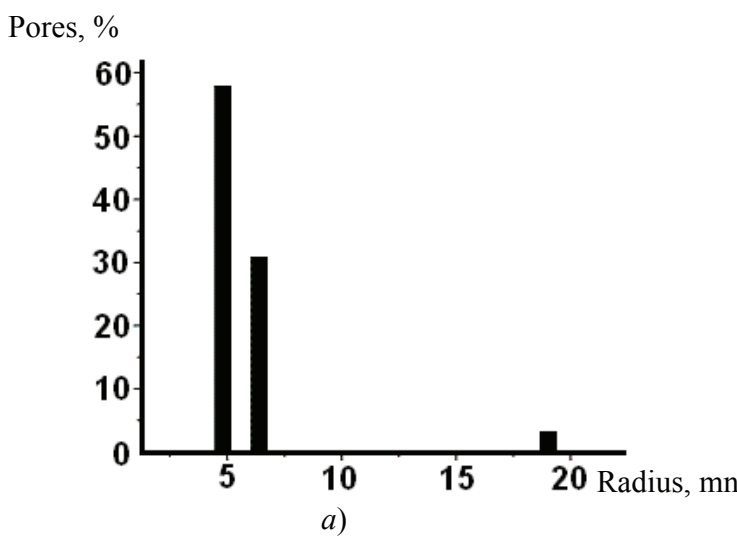

Pores, \%

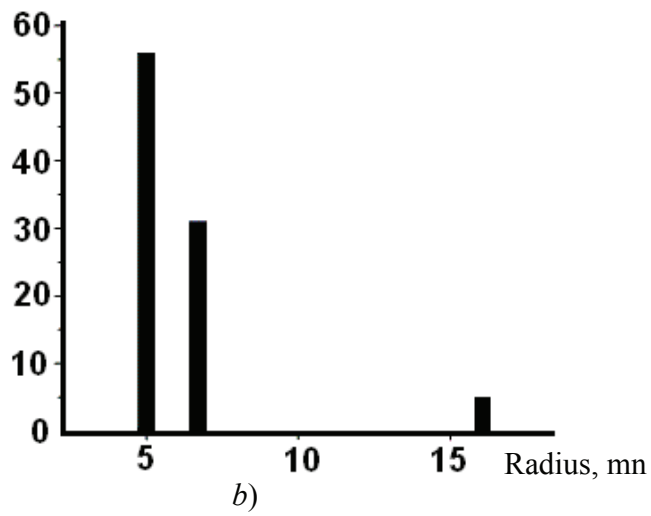

Fig. 9. Distribution of pores in:

$a$ - the ESPA membrane; $b$ - the MGA-95 membrane

respectively, which significantly exceeded $10 \%$ relative to the average radii determined by tangent method. This difference suggests that the sectional shape of the pores with respect to the primary beam is elliptical. Fig. 9 shows the distribution of the relative number of pores in membranes $m_{k}\left(R_{g k}\right), \%$.

Optimal calculated values of the radius of gyration and pore radius for the given membranes are summarized in Table 2.

These numerical values of the pore radius obtained by small-angle X-ray scattering (SAXS) were consistent with those obtained by the hydrodynamic permeability method in [17]. It also demonstrates the correctness of the choice of the method for the study of the radius of gyration and the radius of pores and the experimental data obtained by small-angle X-ray scattering (SAXS).

Table 2

Calculated values of radius

of gyration $\boldsymbol{R}_{g_{k}}$ and pore radius $\boldsymbol{r}_{k}$, nm

\begin{tabular}{ccccccc}
\hline Membrane & $R_{g 1}$ & $r_{1}$ & $R_{g 2}$ & $r_{2}$ & $R_{g 3}$ & $r_{3}$ \\
\hline ESPA & 4.8 & 6.2 & 6.4 & 8.3 & 19 & 25 \\
MGA-95 & 5 & 6.4 & 6.7 & 8.6 & 16 & 20 \\
\hline
\end{tabular}



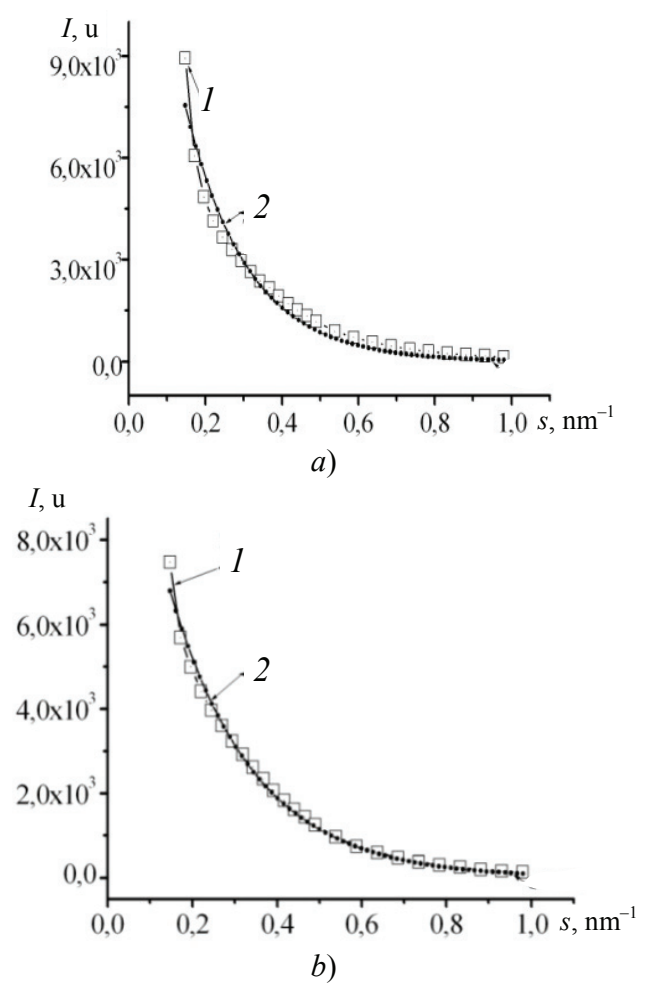

Fig. 10. The correlation between the intensity of small-angle $\mathrm{X}$-ray scattering and the wave vector modulus (s) for: $a$-ESPA; $b$ - MGA-95 membranes;

1 - experimental curve; 2 - theoretical curve

The morphology of the surface of the MGA-95 and ESPA semipermeable membranes was studied on the KRM-1 plant using an X-ray tube with a copper anode and a Ni-filter with a scanning pitch $\theta=1^{\prime}$ in an automatic mode. The exposure lasted $100 \mathrm{~s}$ in the interval range of wave scattering vector $s=0.147-0.98 \mathrm{~nm}^{-1}$, $s=4 \pi \sin \theta / \lambda(2 \theta-$ scattering angle, $\lambda=0.154 \mathrm{~nm})$.

The correlation between the intensity of smallangle X-ray scattering and the wave vector modulus $(s)$ are shown in Fig. 10.

The interval of dependence of small-angle X-ray scattering intensity on the wave vector modulus $(s)$ was calculated by Wolf-Bragg formula

$$
d s=2 \pi \text {. }
$$

This formula connects the linear characteristics of direct and reciprocal spaces, and allows obtaining reliable information about the size of pores in the range of 40 to $6 \mathrm{~nm}$. When considering the dependence $I(s) \sim f(s)$ (Fig. 10), we observed the smoothness of the scattering curves and absence of interference caused by the interparticle interactions $[18,19]$. However, if the graph of the curve for each sample is approximated by an exponential function, the variation of theoretical exponent does not coincide with the experimental curve (Fig. 10).

Hence, the nature of the experimental scattering curves $I(s)$ indicates that the investigated samples of membranes contain scattering localized electron heterogeneities (pores) of different size.

On the curves of $I(s)$ in double logarithmic coordinates $\log (I(s)) \sim \log (s) \quad$ we observed three rectilinear portions, with different angular coefficients (Fig. 11).

This is confirmed by the power law of scattering which is expressed by the formula:

$$
I(s) \sim s^{-a},
$$

which indicates the fractal nature of scattering objects (pores) $[20,21]$.

For the MGA-95 membrane the scattering index $a$ in the range of values $s$ from $0.539-0.98 \mathrm{~nm}^{-1}$ was equal to -3.5 , from $0.136-0.36 \mathrm{~nm}^{-1}$ it was equal to -1.2 , from $0.147-0.1715 \mathrm{~nm}^{-1}$ it was equal to -1.8 . For the ESPA membrane the scattering index in the range of s from $0.585-0.98 \mathrm{~nm}^{-1}$ was $a=-3.6$, in the range of s from $0.2205-0.39 \mathrm{~nm}^{-1}$ it was $a=-1.32$ and in the range of $\mathrm{s}$ from $0.147-0.1715 \mathrm{~nm}^{-1}$ it was $a=-2.25$. As can be seen from the data the pore space of the investigated membranes was formed mainly by the pores of three sizes with multiple levels of spatial structure.

The values of $a=-3.5$ for the MGA-95 membrane and $a=-3.6$ for the ESPA membrane, according to the theory $[18,21]$ correspond to surface scattering from the pores of radius $r_{1}=5.6 \mathrm{~nm}$, $r_{1}=5.5 \mathrm{~nm}$, close to the smooth surface (for a perfect topological surface $a=4$ ). Decreasing values of $a$ indicated scattering from tortuous pores (for straight channels $a=1$ ) with a rough surface [20,21]. Pores of the radius of 9.3 and $9.54 \mathrm{~nm}$ showed the least tortuosity. At the same time pores of radius of 12.9 and $16.8 \mathrm{~nm}$ were more tortuous.

The radius of gyration was determined by the method described in $[18,19]$, i.e., the experimental curve was considered as the sum of the curves corresponding to the individual classes of scattering pores with universal characteristic parameter, namely, the radius of gyration $R_{g}$.

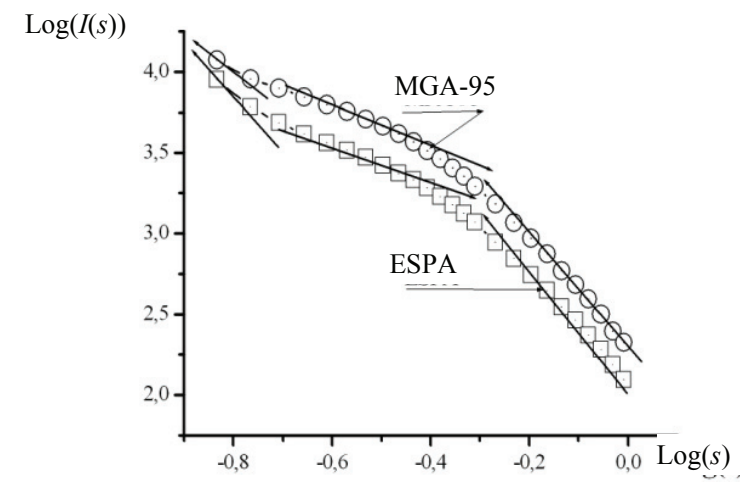

Fig. 11. The dependence of the SAXS intensities on the scattering angle in coordinates $\log I(s)-\log (s)$ for MGA-95 and ESPA membranes 
Refitting the curves $I(s)$ as functions $\ln (I(s))=$ $=f\left(s^{2}\right)$ we obtained semilogarithmic dependence $\ln I(s))=\ln I(0))-s^{2} R_{g}^{2} / 3 \quad$ (Fig. 12), where $I(0)$ is scattering intensity extrapolated to the value $s=0$.

Having distinguished the linear portion of the scattering curve $\ln I(s)=f\left(s^{2}\right)$, and measured the slope of the line, we calculated the radius if gyration by the formula (8).

Further on the calculation procedure for $R_{g k}$ is repeated for the next straight portion of the curve. The radius of gyration and the pore radius are related as in [19].

The intercept $\ln (I(0))$ on $s$-axis, given the background scattering, determines the contribution of a given type of pores to the scattering intensity, thus making it possible to determine their number [13].

$$
R_{g}^{2}=3 r^{2} .
$$

The relative proportion of pores of a given size was determined by the method described in [13, 19], indicating that the energy of scattering at zero diffraction angle is proportional to the volume fraction $m_{k}$ of scattering particles (pores) and calculated as $m_{k} \sim I_{k}(0) / R_{g k}^{3}$.

The average radius of gyration and the average radius of pores can be found by the following Eq. (11).

For the ESPA membrane $r_{\text {mean }}=8.7 \mathrm{~nm}$, $\left(d_{\text {mean }}=17.4 \mathrm{~nm}\right)$, for the MGA-95 $r_{\text {mean }}=7.05 \mathrm{~nm}$ $\left(d_{\text {mean }}=14.1 \mathrm{~nm}\right)$.

The values of the specific surface of the pore space $S / V$ were calculated from the conditions of scattering by inhomogeneities, as a totality of particles in a solid matrix by the formula [19]

$$
S_{\mathrm{sp}}=3.14 m(1-m) C_{4} / Q,
$$

where $m$ equals the sum of $m_{1}+m_{2}+m_{3}$ of volume fractions of pore radii $r_{1}, r_{2}, r_{3}, m_{1}=0.09, m_{2}=0.23$, $m_{3}=0.356$ for the ESPA membrane, and $m_{1}=0.147$,

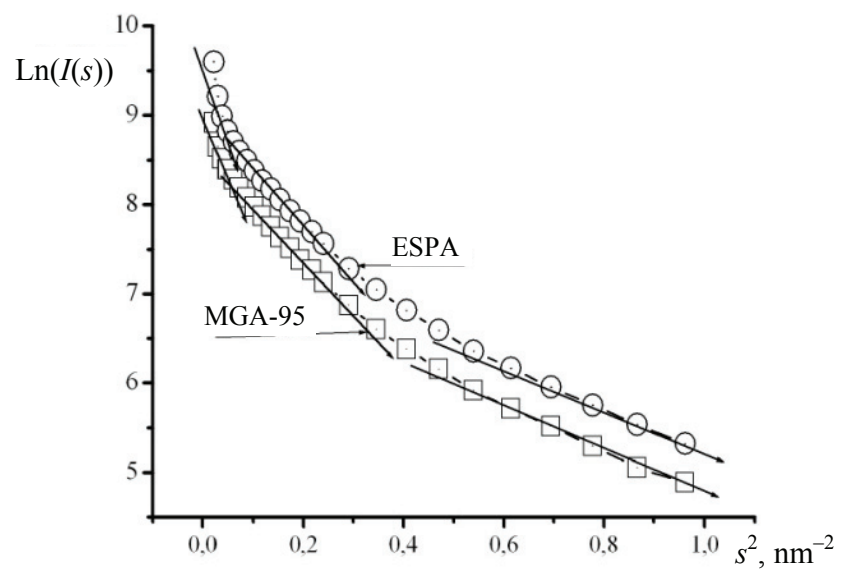

Fig. 12. The dependence of SAXS intensity on the scattering angle in the coordinates $\ln (I(s))-s^{2}$ for the MGA-95 and ESPA membranes

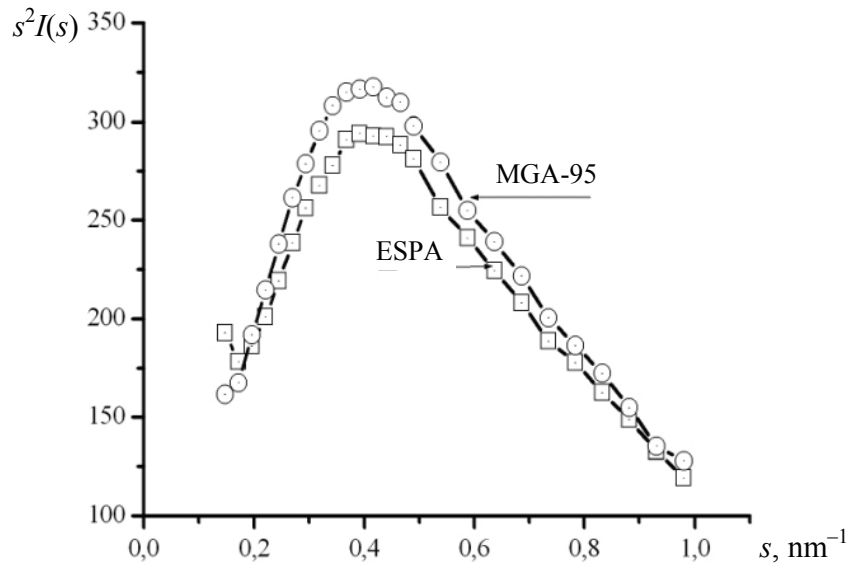

Fig. 13. The dependence of SAXS intensity on the scattering angle in the coordinates $s^{2} I(s) \sim s$

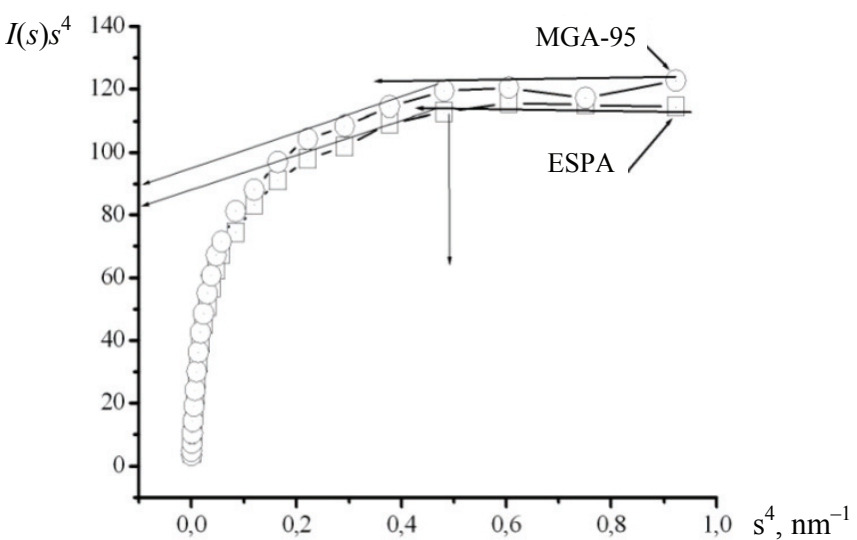

Fig. 14. The dependence of SAXS intensity on the scattering angle in the coordinates $s^{4} I(s) \sim s^{4}$

$m_{2}=0.395, m_{3}=0.2$ for the MGA-95 membrane, $Q$ is the invariant, $C_{4}$ is the Porod constant [19].

The Porod invariant was calculated as the area under the SAXS curve in the coordinates $s^{2} I(s) \sim f(s)$ (Fig. 13) and was equal to $Q=192.75 \mathrm{~nm}^{-3}$ for the MGA-95 membrane, and $Q=181.2 \mathrm{~nm}^{-3}$ for the ESPA membrane.

The Porod constant was determined by the dependence $s^{4} I(s) \sim f\left(s^{4}\right)$ as follows:

$$
I(s) s^{4}-I_{\mathrm{P}} s^{4}=C_{4},
$$

if $s>0.83$ the Porod plateau is formed (Fig. 14).

Then, by extrapolating to $s=0$, we obtained the value of $C_{4}$ [19] for the MGA-95 membrane $C_{4}=29.2 \mathrm{~nm}^{-4}$, and for the ESPA membrane $C_{4}=15 \mathrm{~nm}^{-4}$.

The X-ray scattering study of the structural characteristics of the semipermeable MGA-95 and ESPA membranes resulted in the following conclusions. 


\section{Conclusion}

1. The data obtained confirm that during swelling the supramolecular structure of the membrane material undergoes changes owing to the deformation of both crystalline and amorphous components of the sample phases. Water molecules have a strong tendency to donor-acceptor interactions with potential-forming ions of free surfaces of capillary (porous) medium; they have a disjoining anisotropic effect on the intermolecular heterostructure of the membrane, compressing the amorphous regions of the crystalline lattice.

2. The data on the amorphous regions for dry, swollen and working samples of an MGA-95 semipermeable membrane were obtained and analyzed. The comparison of the diffraction patterns of the new and working membrane samples showed that the application of an external impact factor (pressure gradient) is likely to influence the transport of material, but it does not cause any intramolecular structural changes in the membrane.

3 . The data on the radius of gyration and pore radius obtained by the small-angle scattering method allow for a more accurate physical description of transport mechanism of ions and molecules in capillary (pores), and calculation of kinetic coefficients of membrane separation of solutions.

4. The data on the membrane morphology obtained by the SAXS method showed that the sorption space of MGA-95 and ESPA membranes was actually formed by three kinds of pores with different surface morphology. Pores of a smaller radius had a smoother, while those of a bigger radius were formed by tortuous channels and had a rough surface. The percentage of large radii pores of 12.9 and $16.8 \mathrm{~nm}$ was 20 and $35.6 \%$ for MGA-95 and ESPA membranes, respectively. The calculated values of specific surface for MGA-95 and ESPA membranes were $S_{\mathrm{sp}}=9.15 \cdot 10^{7} \mathrm{~m}^{-1}$ and $S_{\mathrm{sp}}=5.95 \cdot 10^{7} \mathrm{~m}^{-1}$, respectively.

\section{Acknowledgements}

The work was supported by the RF Ministry of Education and Science, No. 2014/219 for 2014-2016.

\section{References}

1. Vendelshteyn B.Yu. (1966). Issledovanie razrezov neftyanyih i gazovih skvazhin metodom sobstvennyih potentsialov [The study of oil and gas well cuttingss by self-potential method]. M.: Nedra. (Rus) (Rus)

2. Mulder M. (1999). Membranyi [Membranes]. M.: Mir

3. Churaev A.V. (1990). Fiziko-himiya protsessov massoperenosa $v$ poristih telah [Physical chemistry of mass transfer processes in porous bodies]. M.: Himiya. (Rus)

4. Karbanova S.N., Pikura N.P., Anisimova L.S., Katyuhin V.E., Romanenko S.V. (2000). Poverhnostnyie yavleniya $i$ dispersne sistemyi [Surface phenomena and disperse systems].Tomsk, Izd. TGU. (Rus)

5. Lazarev S.I., et al (2014). Issledovanie jelektrokineticheskih harakteristik obratnoosmoticheskih polupronicaemyh membran $\mathrm{v}$ vodnyh rastvorah gidrokarbonata natrija [The study of electrokinetic characteristics of semipermeable reverse osmosis membranes in aqueous solutions of sodium hydrogen carbonate]. Sorbtsionnyie $i$ hromatograficheskie protsessyi [Sorption and chromatographic processes], 14 (3), 232-236. (Rus)

6. Shipovskaya A.B. (2009). Fazovyiy analiz sistem efir tsellyulozyi-mezofazogennyiy rastvoritel: Avtoref. ... dis. d-ra him. nauk [Phase analysis of cellulose ether-mesophasegene solvent systems. Dissertation abstract]. Saratov. (Rus)

7. Arisova V.N. (2008). Struktura $i$ svoystva KM. [The Structure and Properties of KM]. Volgograd: VolgGTU. (Rus)

8. Kovalev G.V., Bugaenko L.T. (2002). Plastificirujushhee dejstvie vody na g-obluchennuju celljulozu [The plasticizing effect of water on g-irradiation cellulose]. Vestnik Moskovskogo universiteta [Bulletin of Moscow University], 43 (1), 67-70. (Rus)

9. Ioelovich M.Ya., Veveris G.P. (1987). Himiya drevesinyi [Wood Chemistry], (5), 75-80. (Rus)

10. Kovarskij N.Ja., Kolzunova L.G., and Kalugina I.Ju. (1990) Patent RF 1560280, Sposob poluchenija polupronicaemyh membran [A method for producing semipermeable membranes], Bjul. No 16. (Rus)

11. Peris Agilar, J. (1985) Yavlenie perenosa cherez membranu (The phenomenon of migration through the membrane). (Rus)

12. Kitajgorodskij A. I. (1950) Rentgenostrukturnyj analiz [The X-ray diffraction analysis]. M.-L. GITTL. (Rus)

13. Poraj-Kosice M.A. (1960) Prakticheskij kurs rentgenostrukturnogo analiza. T.2: Uchebnik dlja un-tov [Practical course of X-ray analysis. Vol. 2: A Textbook for Universities]. M: Moscow State University. (Rus)

14. Polikarpov V.M., et al. (2006) Sovremennye metody komp'juternoj obrabotki jeksperimental'nyh dannyh: uchebnoe posobie [Modern methods of computer processing of the experimental data: a tutorial]. Tambov state technical university.

15. Polikarpov V.M. et al (2010) Jeksperimental'noe issledovanie poristoj struktury obratnoosmoticheskih kompozicionnyh membran metodom malouglovogo rentgenovskogo rassejanija [Experimental study of the porous structure of a composite reverse osmosis membrane by small-angle X-ray scattering]. Kondensirovannye sredy i mezhfaznye granicy [Condensed substances and interphase boundaries]. Voronezh, Vol. 12 (4), 382-385. (Rus)

16. Lazarev S.I., et al. (2012) [Experimental and theoretical studies of surface structure of semipermeable reverse osmosis membranes by X-ray scattering]. Vestnik $T G U$ [Bulletin of Tambov State University], 17(4), 1260-1262. (Rus)

17. Lazarev K.S. (2012) Jelektrogiperfil'tracionnaja ochistka stochnyh vod ot reagentov proizvodstva himikatov-dobavok [Electrohyperfiltration treatment of wastewater from reagents of chemical additives]. Tambov. (Rus)

18. Guinier A. (1961) Rentgenografija kristallov [X-ray crystallography]. M., Fizmatgiz. (Rus)

19. Svergun D.I., Feigin L.A. (1986) Rentgenovskoe $i$ nejtronnoe malouglovoe rassejanie [X-ray and neutron small-angle scattering]. M., Nauka. (Rus)

20. Olemskoy A.I., Flat A.Ya. (1993) Issledovanie koncepcii fraktala $\mathrm{v}$ fizike kondensirovannoj sredy [A study of the concept of fractal physics of condensed matter]. Zhurnal uspehi fizicheskoj nauki, Vol. 163 (12), 1-88. (Rus)

21. Lazarev S.I., et al. (2012) Jeksperimental'nye i teoreticheskie issledovanija struktury poverhnosti polupronicaemyh membran metodom rentgenovskogo rassejanija [Experimental and theoretical studies of the surface structure of semi-permeable membranes by X-ray scattering]. Vestnik $D G U$ [Bulletin of the DSU], (6), 234-239 (Rus) 